DOI: 10.12731/2077-1770-2020-1-274-280

УДК 82.09

\title{
ОСОБЕННОСТИ РАЗРУШЕНИЯ «ЧЕТВЁРТОЙ СТЕНЫ» В ПРОИЗВЕДЕНИЯХ ДЖОНАТАНА СТРАУДА
}

\section{Тильки А.Ю.}

Цель. Статья посвящена исследованию понятия «четвёртой стень» в современной англоязычной художественной литературе. Цель исследования заключается в анализе особенностей использования приёма "разрушения четвёртой стены» в произведениях Джонатана Cmpayda “Lockwood \& Co. " и “The Bartimaeus trilogy”.

Методы исследования включают в себя анализ научной литературы, метод сплошной выборки материала и метод лингвистического описания данных.

Результаты. Проанализировав понятие «четвёртой стены» $u$ особенности её «разрушения», а также рассмотрев это явление 6 книгах Дж. Страуда, можно сделать вывод о том, что автор намеренно стирает границы между реальным миром и вымыиленным для достижения образовательной изели и комического эффекта.

Область применения результатов. Полученнье в ходе исследования результаты могут быть использованы на курсах литературоведения, интерпретации текста.

Ключевые слова: «четвёртая стена»; художественная литература; художественный приём; читатель; герой; диалог.

\section{THE PECULIARITIES OF DESTRUCTION OF "THE FOURTH WALL" IN THE WORKS OF JONATHAN STROUD}

\section{Tilki A. Y.}

Purpose. The article is devoted to the study of the concept of "the fourth wall" in modern English-language fiction. The goal of the re- 
search is to analyze the peculiarities of the use of "breaking the fourth wall" technique in the works of Jonathan Stroud Lockwood \& Co. and The Bartimaeus trilogy.

Research methods include the analysis of scientific literature, the method of continuous sampling of material and the method of linguistic description of data.

Results. After analyzing the definition of the term "fourth wall" and the features of its "destruction", as well as considering this phenomenon in the books of Jonathan Stroud, we can conclude that the author deliberately blurs the boundaries between the real world and the fictional to achieve an educational goal and comic effect.

Practical implications. The received results can be used in the courses of literary criticism, interpretation of literary text.

Keywords: "the fourth wall"; fiction; literary method; reader; hero; dialogue.

Понятие «четвёртая стена» впервые было использовано Дени Дидро в XVIII в. в связи с появлением «театрального реализма». Сам термин непосредственно связан с концепцией театра и обозначает воображаемую границу, стену между зрителем и актёром [5]. Иными словами, актёры не обращают внимания на зрителей, полностью сосредотачиваясь на драматическом мире. Такое состояние получило название «публичное уединение», то есть всё происходящее на сцене словно отделено от наблюдателей невидимой стеной. Позднее термин вышел за пределы театра, обозначая собой границы между любым вымышленным миром и его зрителями. Его употребление наблюдалось и в других видах искусства таких, как кино, литература, компьютерные игры и др.

«Четвёртая стена», как и любая другая, может быть разрушена. Чаще всего это происходит в кино. В большинстве случаев именно благодаря фильмам люди узнают о таком понятии, как «четвёртая стена». Если говорить о методах разрушения «четвёртой стены», то они бывают разными:

1) Обращение героя к зрителю. Заключается в том, что персонаж, глядя в камеру, вступает со зрителем в диалог, коммен- 
тирует сюжет, сообщает какую-либо информацию или просто размышляет о чём-то.

2) Взгляд на зрителя. Используется в драматичных моментах для усиления напряжения, в качестве приглашения принять участие в жутком действии.

3) Отказ от условности. Предполагает открытый выход персонажей за пределы условного пространства, то есть в кадре появляются камеры, микрофоны, члены съёмочной группы, сам режиссёр. Делается это для достижения комического эффекта.

4) Отказ от «четвёртой стены». В данном случае действие выдаётся за реальное. Это может быть стилизация под репортаж или съёмка происходящего на любительскую камеру.

Не многие знают, что приём разрушения «четвёртой стены» употребляется и в художественной литературе. Само понятие «четвёртой стены» здесь определяется тем, что персонаж не подозревает о вымышленной природе своего мира и ведёт себя соответствующим образом. А разрушение границы между реальностью и вымыслом происходит тогда, когда литературный персонаж напрямую обращается к читателю с помощью реплики или действия. Бывают случаи, когда в мире книги появляются реальные люди, в особенности сам автор, становятся частью истории. Например, встреча персонажей цикла «Тёмная башня» со Стивеном Кингом. Считается, что такой подход даёт возможность читателю глубже погрузиться в вымышленный мир произведения, заставляет поверить, что все события происходят на самом деле [5].

В данной статье мы рассмотрим понятие «четвёртой стены» на примере произведений Джонатана Страуда, особенность творчества которого заключается в том, что его персонажи берут роль рассказчика на себя и ведут диалог непосредственно с читателем: "You might notice I'd slightly abandoned my attempts at keeping it light-hearted. That was because the thing in the study had already picked up on my agitation, and was now drifting through the door" [6, с. 35]. Здесь мы видим, как героиня объясняет, почему накричала на своего друга.

Иногда герои отвечают на немые вопросы читателей: “Why? Because, entirely unexpectedly, we had stepped out of our world and into another place. Where was this place? That's hard to say" [8, c. 23]. 
Или знакомят с другими персонажами: "Have I mentioned Kipps before? He's a team leader for the Fittes Agency's London Division... Being diplomatic, I'd say Kipps was a slightly built young man in his early twenties, with close-cut reddish hair and a narrow, freckled face. Being undiplomatic (but more precise), I'd say he's a pint-sized, pug-nosed, carrot-topped inadequate with a chip the size of Big Ben on his weedy shoulder. A sneer on legs. A malevolent buffoon. He's too old to be any good with ghosts, but that doesn't stop him wearing the blingiest rapier you'll ever see, weighed down to the pommel with cheap paste jewels" [7, c. 21].

Особое внимание следует уделить циклу Дж. Страуда «Трилогия Бартимеуса». В данной трилогии повествование ведётся от лица трёх персонажей, но особенно сильно запоминаются главы, написанные от лица джинна Бартимеуса, так как этот герой постоянно «ломает четвёртую стену». Эти главы сопровождаются примечаниями, содержащими собственные мысли и комментарии относительно сюжета и поступков других персонажей. Сам Дж. Страуд упоминал, что джинн со своим саркастичным и грубоватым характером идеально подходит на роль рассказчика, и поэтому расставлять его ехидные сноски автору было вдвойне интересно. Сноски помещаются в квадратные скобки и содержат разного рода информацию. Это могут быть забавные пояснения: "No magical alarm sounded, though I did hit my head five times on a pebble [Once each on five pebbles. Not the same pebble five times. Just want to make that clear. Sometimes you human beings are so dense]" [9, с. 23]. Данное примечание избавляет от недоразумений и показывает, что персонаж не настолько глупый, каким его могли бы считать.

Или воспоминания джинна: “That might be fun: there was bound to be a way of misinterpreting his request and upsetting him [One magician demanded I show him an image of the love of his life. I rustled up a mirror]" [9, с. 15]. Таким образом, читатель также узнаёт немного о прошлом героя.

Более того, примечания включают в себя объяснения устройства мира, в котором происходят события: "My leathery wings moved in strong, slow beats; my eyes scanned the seven planes to the horizon 
[The Seven Planes: The seven accessible planes are superimposed upon each other, and each reveals certain aspects of reality. The first includes ordinary material things (trees, buildings, humans, animals, etc.), which are visible to all; the other six contain spirits of various kinds going quietly about their business...]" [10, с. 10]. Дж. Страуд убеждён, что никто не расскажет о своём мире лучше, чем сам персонаж.

Кроме того, приём «разрушения четвёртой стены» служит образовательной цели. Например, когда герой произведения упоминает исторические факты, которые переплетаются с сюжетом, но при этом не теряют своей достоверности. В книге «Кольцо Соломона» в разговоре двух джиннов встречается название города Кадеш. Это реально существовавший город, и джин Бартимеус в примечании рассказывает о битве, которая имела место на территории этого города $[11$, с. 237]. В произведении во время одного из диалогов также заходит речь о городе Эриду. Благодаря сноскам читатель может создать в своей голове образ этого города [11, с. 15].

Разрушение «четвёртой стены»- интересный приём, и Дж. Страуд мастерски использует его, стирая границы между реальным миром и вымышленным. Помимо этого, к этому приёму обращаются и для того, чтобы добиться юмористического эффекта. А поскольку целевая аудитория писателя - это дети и подростки, то приём «разрушения четвёртой стены» применяется также и для снятия напряжения в тех случаях, когда герои находятся в опасной ситуации.

\section{Список литературы}

1. Комаров А.С. Межличностное взаимодействие читателя, автора и персонажа художественного текста // Вестник МГИМО университета №5 (26). 2012. С. 215-220.

2. Сафонова Е.В. Формы, средства и приёмы создания комического в литературе // Молодой ученый. 2013. № 5. С. 474-478.

3. Тютелова Л.Г. Проблема «четвертой стены» в русской драме XIX века // Вестник ЮУрГГПУ. 2015. о 1. С. 286-293.

4. Федоткин С.В. К определению понятия «фиктивный зритель» в кино // Вестник славянских культур. 2017. Том 45. С. 232-240. 
5. Bell E. Theories of Performance. Los Angeles: SAGE Publications, Inc. 2008. 320 p.

6. Stroud J. Lockwood \& Co.: The Screaming Staircase. US: DisneyHyperion. 2013. 416 p.

7. Stroud J. Lockwood \& Co.: The Whispering Skull. US: Disney-Hyperion. 2014. 435 p.

8. Stroud J. Lockwood \& Co.: The Empty Grave. US: Disney-Hyperion. 2017. $448 \mathrm{p}$.

9. Stroud J. The Amulet of Samarkand. US: Hyperion Books for Children. 2003. $462 \mathrm{p}$.

10. Stroud J. The Golem's Eye. US: Disney-Hyperion. 2006. 562 p.

11. Stroud J. The Ring of Solomon. US: Disney-Hyperion. 2012. 416 p.

\section{References}

1. Komarov A.S. Mezhlichnostnoe vzaimodeistvie chitatelya, avtora I personazha khudozhestvennogo teksta [Interpersonal interaction of reader, author and character of a fiction literature text]. Vestnik MGIMO. №5 (26). 2012, pp. 215-220.

2. Safonova E.V. Formi, sredstva i priemi sozdanija komicheskogo v lirerature [Means of creating comical in literature]. Molodoy ucheny. 2013. No 5, pp. 474-478.

3. Tutelova L.G. Problema «chetvertoy steny» v russkoy drame XIX veka [Problem of the "fourth wall" in Russian drama of the XIX century]. Vestnik YuUrGGPU. 2015. No 1, pp. 286-293.

4. Fedotkin S.V. K opredeleniyu ponyatiya «fiktivnyy zritel'» v kino [Defining the fictive viewer (narratee) in cinema]. Vestnik slavianskikh kul'tur [Bulletin of Slavic Cultures]. 2017. Volume 45, pp. 232-240.

5. Bell E. Theories of Performance. Los Angeles: SAGE Publications, Inc. 2008. 320 p.

6. Stroud J. Lockwood \& Co.: The Screaming Staircase. US: Disney-Hyperion. 2013. $416 \mathrm{p}$.

7. Stroud J. Lockwood \& Co.: The Whispering Skull. US: Disney-Hyperion. 2014. 435 p.

8. Stroud J. Lockwood \& Co.: The Empty Grave. US: Disney-Hyperion. 2017. 448 p. 
9. Stroud J. The Amulet of Samarkand. US: Hyperion Books for Children. 2003. 462 p.

10. Stroud J. The Golem's Eye. US: Disney-Hyperion. 2006. 562 p.

11. Stroud J. The Ring of Solomon. US: Disney-Hyperion. 2012. 416 p.

\section{ДАННЫЕ ОБ АВТОРЕ}

Тильки Александра Юрьевна, студент 4 курса Института межкультурной коммуникации и международных отношений по направлению подготовки «Фундаментальная и прикладная лингвистика»

Белгородский государственный наџионально-исследовательский университет

ул. Победы, 85, г. Белгород, Белгородская обл., 308015, Российская Федерация

aleksandratilki@gmail.com

\section{DATA ABOUT THE AUTHOR}

Tilki Aleksandra Yurievna, $4^{\text {th }}$-year Student of Institute of Cross-cultural Communications and International Relations in the field of Fundamental and applied linguistics

Belgorod National Research University

85, Pobeda Str., Belgorod, 308015, Russian Federation

aleksandratilki@gmail.com 